\title{
O Desvio no Fluxo Composicional ${ }^{1}$
}

\author{
Deviation in the Compositional Flow
}

\author{
Bruno Yukio Meireles Ishisaki \\ Denise Hortência Lopes Garcia \\ Universidade Estadual de Campinas
}

\begin{abstract}
Resumo: Neste texto buscamos compreender, no contexto dos processos criativos em composição musical, as características do desvio no fluxo composicional a partir da perspectiva do virtual deleuziano. Acreditamos que a manifestação do desvio é um acontecimento inevitável dentro do fluxo criativo que, ao produzir diferença por meio da atualização, promove uma dessemelhança entre o que é criado e o que é pensado. Neste caso, a atualização contribuiria para um processo mais espiralar do que linear, em oposição à imagem do fluxo criativo como um trajeto teleológico em linha reta (que iria das ideias para os estados de coisas).
\end{abstract}

Palavras-chave: Virtual; Atualização; Composição Musical; Desvio; Deleuze

\begin{abstract}
In the context of creative processes in musical composition, this paper seeks to understand the deviation characteristics in the compositional flow, from the perspective of Deleuzian virtual. We believe that the deviance manifestation is an inevitable event within the creative flow, and that by producing difference through actualization it also promotes a dissimilarity between what is created and what is thought. In this case, the update would contribute to a more spiral rather than linear process, opposing the image of creative flow as a straight-line teleological path (that would go from idea to state of things).
\end{abstract}

Keywords: Virtual; Actualization; Musical Composition; Deviation; Deleuze

${ }^{1}$ O presente trabalho foi realizado com apoio da Coordenação de Aperfeiçoamento de Pessoal de Nível Superior - Brasil (CAPES) - Código de Financiamento 001. 
MUSICA THEORICA Revista da Associação Brasileira de Teoria e Análise Musical 2019, v. 4, n. 1, p. 234-254-Journal of the Brazilian Society for Music Theory and Analysis@ TeMA 2019 - ISSN 2525-5541

\section{Teleologia e composição musical}

Mesmo as escolas dos estilos composicionais mais díspares frequentemente trazem um traço comum em seus discursos: falam da ideia musical como norteadora do processo criativo. Assim, o planejamento composicional se configuraria como um projeto teleológico que teria por finalidade a materialização fidedigna de um determinado conjunto de Ideias. Tal noção, apesar de não ser hegemônica, está bastante presente nas práticas derivadas dos idealismos de um desenvolvimentismo temático que se fundamenta, em um primeiro momento, no tratamento motívico e na macroforma, para depois se estender aos campos texturais para o tratamento timbrístico, os perfis rítmicos e as coleções intervalares, até alcançar todo tipo de categorização teórica que se baseie em uma noção de identidade.

Em todo caso, estamos falando especificamente de um tipo de pensamento teleológico fundamentado na representação. Neste contexto, é sempre inescapável a comparação entre o que foi feito e o que foi pensado - por exemplo, uma performance musical como representação da partitura (ou vice-versa). Em seu artigo Virtual works - Actual things, Paulo de Assis expõe o panorama da representação como um problema ontológico no campo da teoria musical:

Apesar de suas profundas diferenças e discussões, as três teorias mais abrangentes existentes - Platonismo, nominalismo, ficcionalismo compartilham um traço comum: todas elas são sustentadas por um modelo de representação do pensamento e por práticas musicais de representação. Há sempre a performance ou apreensão de algo "como" algo, ou a performance "de" algo. Qualquer que seja o modo de perceber o aqui-e-agora (uma performance, uma gravação, uma descrição), ele é a "representação" de algo mais. Platonistas insistem na primazia de uma ideia original e de estruturas sonoras perfeitamente encapsuladas que podem ser representadas através de performances. Nominalistas focam nas entidades materiais internas à prática musical, rejeitando abstractas ${ }^{2}$ mas mantendo a suposição da performance como algo baseado na repetibilidade e variabilidade de uma obra claramente bem articulada, porém gerada imanentemente, que crucialmente pré-existe à performance, e sobre a qual a performance é comparada, reintroduzindo assim uma entidade transcendental no panorama. Para os ficcionalistas não há obras de fato, mas por meio de suas

\footnotetext{
2 Abstractas referem-se, aqui, às operações intelectuais que consistem em "isolar, por exemplo, num conceito, um elemento à exclusão de outros, do qual então se faz abstração" (Durozoi; Roussel 1993, p. 11). Trata-se, portanto, de exprimir relações e de tudo aquilo que pode, em termos de pensamento, ser considerado geral em uma determinada classe de fenômenos.
} 
construções das obras "como se elas existissem", eles cometem - em termos práticos - o mesmo modelo de performance como apresentando (ou representando) uma entidade musical já dada (mesmo que seja fantasmática) (Assis 2018, p. 22).

O pensamento teleológico que parte da ideia aos estados de coisas está intimamente conectado a uma lógica da representação no processo composicional, já que “a própria noção de representação implica em algo anterior que tem a capacidade de ser representado" (Assis 2018, p. 22); ou seja, se há uma ideia que antecede a feitura de uma composição musical, esta ideia funda uma teleologia e pressupõe métodos mais ou menos eficientes para se fazer existir como coisa no mundo. Pensados desta forma, esses processos composicionais são todos tributários de um modelo ontológico que irá encontrar sua origem em Platão. Segundo Assis,

Surpreendentemente, as maiores e mais abrangentes ontologias musicais existentes (mesmo aquelas que não são oficialmente classificadas como "Platônicas") estão conectadas com a teoria das Ideias de Platão. As questões fundamentais das diversas ontologias musicais assumem a existência de obras musicais identificáveis e estáveis (sejam elas abstracta ou concreta), ${ }_{1}^{3}$ de sujeitos incorruptíveis capazes de apreendê-las de forma imaculada, e de uma conexão transparente entre a codificação escrita de uma obra e sua manifestação sonora na performance. Essas ontologias não levam em conta as condições intensivas e energéticas e seus processos de chegar a ser, nem as complexidades de sua transmissão através do tempo e da história (Ibidem, p. 24).

Contudo, todo compositor conhece as neuroses e as alegrias do desvio. Sabemos que há um abismo entre o que se registra em notação musical e o que acontece na performance. Do mesmo modo, todo compositor experimenta, em algum momento da composição de sua música, a frustração de ver sua ideia inicial ser desviada para um caminho que desfigura totalmente o planejamento composicional. Mas se há uma neurose, ela acontece por nos apoiarmos demasiadamente na ilusão da identidade, por confiarmos demais na prevalência da ideia sobre as coisas do mundo; em outras palavras, por sermos platônicos demais. Assis fala da possibilidade de se pensar uma ontologia da teoria musical

\footnotetext{
${ }^{3}$ Durozoi e Roussel comentam que "é qualificada de concreta qualquer circunstância vivida em sua dimensão social e histórica por cada homem na situação" (Ibidem, p. 98). Concreta tem a ver, portanto, com aquilo que é individual e circunstancial e se opõe à noção de abstracta, que é generalizante e relacional.
} 
MUSICA THEORICA Revista da Associação Brasileira de Teoria e Análise Musical 2019, v. 4, n. 1, p. 234-254-Journal of the Brazilian Society for Music Theory and Analysis @ TeMA 2019 - ISSN 2525-5541

que possa superar a neurose dos platonismos; que, ao invés de fazer subir categorizações, classes e espécies, possa nos auxiliar na construção de uma imagem do pensamento que corresponda melhor àquilo que há de real nos processos de criação de música:

Assim, tal imagem do pensamento precisa também reverter o Platonismo, ${ }^{4}$ no senso estrito de redirecionar as distinções fundamentais entre ícones e fantasmas, entre imagens e simulacros. Em poucas palavras, ela tem que excluir as hierarquias de categoria e a transcendência idealista (Ibidem, p. 25).

Neste trabalho, buscamos entender os aspectos daquilo que seria chamado de "desvio" dentro de uma perspectiva platônica (o simulacro ${ }^{5}$ seria a consequência atual dessa noção). Entendemos que o desvio é um aspecto imanente incontornável nas práticas de criação; assim, ao invés de ser preterido e evitado, propomos como alternativa um estudo que possa delinear os atributos que fazem dele um elemento potente no fluxo composicional.

Nos debruçaremos, daqui em diante, sobre os conceitos de "virtual" e "atual", tendo como principais referências os filósofos Henri Bergson, Gilles Deleuze e Pierre Lévy. A partir do estudo dos conceitos do virtual e do atual, será possível construir entendimento do fluxo criativo que não dependa mais de um princípio idealista ou de uma trajetória teleológica, permitindo a emergência de outra imagem do desvio no processo composicional.

\footnotetext{
${ }^{4} \mathrm{O}$ projeto de reversão do platonismo empreendido por Deleuze tem a ver com a valorização do simulacro, enquanto acontecimento imanente, em detrimento da superioridade atribuída por Platão à semelhança e à noção de "cópia". A proposta de reversão platônica encontra suas origens em Nietzsche, e é a partir deste autor que Deleuze pensa a sua reversão - na qual o simulacro surge como coisa em si, sem fundamento (daí o termo a-fundamento que utilizaremos mais à frente) nem semelhança com a Ideia, mas conectado a ela e trazendo para a atualização o desvio que sempre foi inerente ao virtual de direito. Enquanto Platão condena os simulacros, Deleuze vê neles a potência para a criação do novo, inaugurando a possibilidade de um pensamento em processos criativos no qual o objeto não é o fim do processo e não está separado, em termos Reais, nem da Ideia, nem do fluxo que percorre a ambos.
}

${ }^{5}$ Em Diferença e Repetição, Deleuze escreve que "por simulacro não devemos entender uma simples imitação, mas antes o ato pelo qual a própria ideia de um modelo ou de uma posição privilegiada é contestada, subvertida" (Deleuze 2018, p. 99). Para um contato mais aprodundado com o conceito de "simulacro" em Deleuze, ver os textos Platão e o Simulacro e Lucrécio e o Simulacro, ambos apêndices do livro Lógica do Sentido (2011). 


\section{O virtual e o atual}

O termo "virtual" está originalmente relacionado à noção de potência. ${ }^{6}$ Pierre Lévy reforça, em O que éo Virtual?, as definições que contornam o conceito, apontando a origem etimológica do termo:

A palavra virtual vem do latim medieval virtualis, derivado por sua vez de virtus, força, potência. Na filosofia escolástica, é virtual o que existe em potência e não em ato. $\mathrm{O}$ virtual tende a atualizar-se, sem ter passado, no entanto, à concretização efetiva ou formal. A árvore está virtualmente presente na semente. Em termos rigorosamente filosóficos, o virtual não se opõe ao real mas ao atual: virtualidade e atualidade são apenas duas maneiras de ser diferentes (Lévy 2011, p. 15).

Para Aristóteles (2002, p. 403), “algo é em potência se o traduzir-se em ato daquilo que se diz ser ele em potência não implica nenhuma impossibilidade". Nesse sentido, o virtual pode ser entendido como um campo formado por complexos de tendências que ainda não estão fixadas no ato, abarcando uma abertura para o porvir na qual todos os polos, oposições e antagonismos coexistem entre si, tal como Deleuze (2012, p. 81) aponta quando escreve que "a coexistência de todos os graus, de todos os níveis, é virtual, somente virtual". O virtual abriga todas as gradações e detém uma realidade própria, pois ele "não se opõe ao real, mas apenas ao atual. O virtual possui uma plena realidade como virtual" (Idem 2018, p. 276), e aquilo que é potência só deixa de sê-lo quando se torna ato: "o ato é o existir de algo, não porém no sentido em que dizemos ser em potência" (Aristóteles 2002, p. 409).

Em Deleuze, a ênfase em sua própria realidade afastará o virtual de uma mera presença prévia - a realidade do virtual não é menor que a do atual. Conforme escreve, "aquilo que chamamos de virtual não é algo ao qual falte realidade, mas que se envolve em um processo de atualização ao seguir o plano que lhe dá sua realidade própria" (Deleuze 2002, p. 16), desviando-se, assim, da noção aristotélica que sugere pesos distintos de realidade para o virtual e o atual. Pierre Lévy considera que

[...] o virtual, rigorosamente definido, tem somente uma pequena afinidade com o falso, o ilusório, o imaginário. Trata-se, ao contrário, de um modo de

\footnotetext{
${ }^{6}$ A palavra "virtual" correspondendo à tradução latina do termo aristotélico para "potência" é assim definida no Dicionário de Filosofia: "a virtualidade designa em Aristóteles o que tende a se realizar e que só existe em potência, e não em ato" (Durozoi; Roussel 1993, p. 485).
} 
MUSICA THEORICA Revista da Associação Brasileira de Teoria e Análise Musical 2019, v. 4, n. 1, p. 234-254-Journal of the Brazilian Society for Music Theory and Analysis@ TeMA 2019 - ISSN 2525-5541

ser fecundo e poderoso, que põe em jogo processos de criação, abre futuros, perfura poços de sentido sob a platitude da presença física imediata (Ibidem p. 12).

O virtual não deve ser entendido como sinônimo de indeterminação - pelo contrário, sua realidade é constituída por estruturas, relações e singularidades. $\mathrm{O}$ que caracteriza o virtual é a ausência de uma existência em ato, de uma consistência (de objeto ou de corpo) que dê a essas relações um aspecto fixo, que o torne, enfim, atual. Deste modo, podemos dizer que o virtual corresponde à porção ideal do objeto (Deleuze 2018, p. 276-277).

$\mathrm{O}$ virtual determina a porção ideal do objeto, aquilo que o torna completo - o que não implica necessariamente que ele esteja inteiro, pois só pode sê-lo no atual; assim, "há, pois, outra parte do objeto, que se encontra determinada pela atualização" (Deleuze 2018, p. 277):

[...] deve-se distinguir cuidadosamente o objeto como completo e o objeto como inteiro. O completo é apenas a parte ideal do objeto, aquela que, na Ideia, participa com outras partes de objetos (outras relações, outros pontos singulares), mas que nunca constitui uma integridade como tal. O que falta à determinação completa é o conjunto das determinações da existência atual (Ibidem).

O objeto completo pode, portanto, ser entendido como a porção ideal do objeto, enquanto o objeto inteiro implica em uma atualização do mesmo. É no virtual que reside o complexo problemático da ideia: voltando ao exemplo de Pierre Lévy, o problema da semente é como se tornar árvore; a semente é a ideia que, atualizada, adquire uma compleição de objeto inteiro (árvore) que não se assemelha à do objeto completo da ideia (a semente). As soluções da problemática não se assemelham às suas condições, já que "a atualização é pensada como um processo verdadeiramente criador, pois ela produz respostas que não guardam nenhuma semelhança com os problemas virtuais que a engendraram" (Henriques 2016, p. 190). Pois

O virtual tem a realidade de uma tarefa a ser cumprida, assim como a realidade de um problema a ser resolvido; é o problema que orienta, condiciona, engendra as soluções, mas estas não se assemelham às condições do problema. Bergson portanto tinha razão ao dizer que, do ponto de vista da diferençação, mesmo as semelhanças que surgem nas linhas de evolução divergentes (por exemplo, o olho como órgão "análogo") devem ser, primeiramente, referidas à heterogeneidade no mecanismo de produção (Deleuze 2018, p. 281). 
Há, na terminologia deleuziana, uma importante distinção entre a diferenciação e a diferençação; para Deleuze (Ibidem, p. 277), "enquanto que a diferenciação determina o conteúdo virtual da Ideia como problema, a diferençação expressa a atualização desse virtual e a constituição das soluções (por integrações locais)". É esta diferençação que faz com que o virtual não se assemelhe ao atual. Podemos, nesse momento, evocar outra imagem arbórea, desta vez uma de Paul Klee (1971, p. 35-36), na qual o artista metaforiza os vetores do processo criativo imaginando-o como a constituição de uma árvore, partindo da seiva (virtual) para as folhagens (atual): neste exemplo, Klee sugere que o artista é um mediador, ele está no tronco, entre o virtual e o atual, atravessado por forças aquém e além de sua subjetividade; a presença de um virtual que se atualiza se dá pela diferençação, pela construção de uma solução da raiz para a folhagem.

Embora a metáfora da árvore de Klee (por nos apresentar uma imagem compartimentada do processo criativo e servir para ilustrar a diferençação na atualização do virtual) pareça tentadora por seu apelo e concisão, devemos alertar para o fato de que o virtual não é a mera efetuação de ideias em um plano material; assim, o virtual não deve ser pensado como um campo ideal que apenas adquire uma materialidade atual. Neste ponto, cabe apontar uma distinção entre o virtual e o possível feita por Deleuze (2018, p. 279): “o possível opõe-se ao real; o processo do possível é, pois, uma 'realização'. O virtual, ao contrário, não se opõe ao real, pois ele possui uma realidade plena. Seu processo é a atualização". O conceito de possível tem a ver com a efetivação estrita de uma estrutura ou forma (Lévy 2011, p. 16); contudo, essa efetivação possui um caráter retroativo. O possível não é prévio ao real: ele é uma projeção do real no passado. Apesar do possível poder ser entendido como uma forma a priori, é necessário que se perceba, à luz de Bergson, a sua modalidade de acontecimento, que contradiz de imediato o conceito de possível como algo prévio ao real.

Segundo Bergson (2006, p. 114), “o possível é apenas o real com, em acréscimo, um ato do espírito que repele sua imagem para o passado assim que ele se produziu". Em termos práticos, o possível habita o passado e é percebido como se fosse um a priori, mas ele sempre acontece a posteriori, sendo um produto do real - assim, o real precede o possível. Deleuze (2018) reforça o conceito bergsoniano ao dar continuidade ao desenvolvimento da distinção entre o possível e o virtual em Diferença e Repetição: 
MUSICA THEORICA Revista da Associação Brasileira de Teoria e Análise Musical 2019, v. 4, n. 1, p. 234-254-Journal of the Brazilian Society for Music Theory and Analysis @ TeMA 2019 - ISSN 2525-5541

Em segundo lugar, o possível e o virtual se distinguem porque um remete à forma de identidade no conceito, ao passo que o outro designa uma multiplicidade pura na Ideia, que exclui radicalmente o idêntico como condição prévia. Enfim, na medida em que o possível se propõe à "realização", ele próprio é concebido como a imagem do real, e o real como semelhança do possível. Eis porque se compreende tão pouco o que a existência acrescenta ao conceito, duplicando o semelhante com o semelhante. É esta a tara do possível, tara que o denuncia como produzido posteriormente, fabricado retroativamente, feito à imagem daquilo a que ele se assemelha (Deleuze 2018, p. 280).

Aquilo que é possível só pôde sê-lo porque antes houve o real. Em um contexto de criação artística, Bergson (2006, p. 115) irá escrever "que um homem de talento ou de gênio surja, que ele crie uma obra: ei-la real, e por isso mesmo, ela torna-se retrospectivamente ou retroativamente possível". Podemos considerar que, a partir de Bergson, o possível pode ser imaginado como efetuação de uma forma, mas deve ser pensado em realidade como um acontecimento a posteriori; assim, não deve ser tomado (como o é no senso comum) como o fundamento de um idealismo identitário; tampouco deve ocupar uma posição transcendental em relação ao real. A negação de tal posição nos leva, portanto, partindo do ponto de vista da composição musical, a um processo que foge à mera tradução das ideias musicais em cópias mais ou menos perfeitas no mundo; consequentemente, o real será o palco para o surgimento da novidade e da imprevisibilidade que ele não poderia portar se fosse apenas causalidade e mecanicismo ou mera efetivação de conceitos:

Que possamos inserir algo real no passado e trabalhar assim de marcha a ré no tempo, nunca o pretendi. Mas que possamos ali alojar o possível, ou antes, que o possível vá ali se alojar por si mesmo a todo instante, isto não é de se duvidar. Ao mesmo passo que a realidade se cria, imprevisível e nova, sua imagem reflete-se atrás dela no passado indefinido; descobre-se assim ter sido, desde sempre, possível; mas é nesse momento preciso que começa a têlo sido sempre, e eis porque eu dizia que sua possibilidade, que não precede sua realidade, a terá precedido uma vez que a realidade tiver aparecido. $\mathrm{O}$ possível é, portanto, a miragem do presente no passado (Bergson 2006, p. 115).

O possível não é o real menos alguma coisa (como se fosse um conceito menos sua efetivação); para Bergson (Ibidem, p. 116) é justamente o contrário: o possível constitui-se como o real mais uma operação do pensamento que o coloca no passado. Considera-se, desse modo, que o possível não é um fantasma prévio 
à realidade, carente de materialidade; ele de fato surge junto com o real, mas sem habitá-lo no devir: somente no momento em que o real surge no presente, o possível passa a habitar o passado.

Bergson (Ibidem, p. 118) nos oferece uma reflexão acerca do possível no contexto de criação artística: “todas essas considerações se impõem quando se trata de uma obra de arte. Acredito que acabaremos por achar evidente que o artista cria o possível ao mesmo tempo que o real quando executa sua obra". Aqui, o real passa a ser o lugar de produção da novidade, do inesperado, da liberdade, e o possível se torna a consequência do exercício desta liberdade. Ele ainda (Ibidem, p. 119) desenvolve as implicações desta perspectiva, arrematando que é o real que traz em si a possibilidade de existir, ao contrário do senso comum que imagina o possível como algo preexistente que de alguma forma se efetua e adquire realidade.

O possível, ao existir a partir do real, marca no passado o desenho das zonas limítrofes do atual, cujos contornos são aqueles impostos pelos obstáculos que o co-produzem na diferençação. Assim, os processos composicionais não precisam ser pensados a partir da mera efetivação de possíveis no real (ou, no caso da composição musical, da transposição fiel de ideias musicais em notação ou performance); tampouco basta que sejam pensados como fluxogramas, algoritmos, projetos automatizados ou mecanicamente executados. Em termos absolutos, pouco pode ser dito a respeito de um suposto "sucesso" ou "fracasso" de um processo criativo, já que tais processos, no âmbito da composição musical, estarão sempre vinculados a uma atualização que diferençará a porção virtual presente em uma ideia musical.

Apesar dos objetivos serem outros e das possíveis distinções conceituais e terminológicas entre o presente trabalho e o campo da crítica genética, há de se levar em conta o que a pesquisadora Cecília Salles diz ao comentar que o processo criativo

[...] pode ser visto como um movimento falível com tendência, sustentado pela lógica da incerteza. Um percurso que engloba a intervenção do acaso e abre espaço para o mecanismo de raciocínio responsável pela introdução de ideias novas. Como se pode perceber, essa visão de processo com tendência não envolve uma visão teleológica baseada em progresso linear ou prédeterminação de fins. A própria ideia de criação implica desenvolvimento, crescimento e vida; consequentemente, não há lugar para metas estabelecidas a priori e alcances mecânicos (Salles 1998, p. 27). 
MUSICA THEORICA Revista da Associação Brasileira de Teoria e Análise Musical 2019, v. 4, n. 1, p. 234-254-Journal of the Brazilian Society for Music Theory and Analysis @ TeMA 2019 - ISSN 2525-5541

Em ressonância com a metáfora da árvore de Klee, para Salles o que é produzido não se assemelha ao que foi concebido de início. O processo de atualização desvia o resultado final de seu planejamento prévio, pois este planejamento não é um agrupamento de conceitos completamente nítidos a serem efetivado no real, e sim um conjunto de ideias detentoras de porções virtuais, um aglomerado de problemáticas com potência para a multiplicidade que adquirirá outra compleição ao se atualizar:

O processo de criação é o lento clarear da tendência que, por sua vagueza, está aberta a alterações. $O$ final pode ser que nada tenha a ver com a "maquete inicial", pois o plano não tem nada da experiência que se adquire na medida em que vai se escrevendo a história (Ibidem, p. 31).

Pensemos nestes termos levando em consideração que aquilo que é virtual sempre conterá um complexo problemático (a diferenciação) que se resolverá na atualização - esta com seus desvios, obstáculos e deformações (diferençação) -, enquanto o possível é o real viabilizado, que se joga ao passado preservando estrutura, forma e operando conceitos a partir do viés da semelhança. A atividade criativa se dá entre o virtual e o atual. Nesse contexto, quando dizemos que a arte engendra novas realidades, não estamos simplesmente evocando uma metáfora: por ser criação, ela consiste nos resultados dos acontecimentos, nos produtos da atualização e do virtual, sendo, de fato, produção de realidade.

A atualização leva em conta, na diferençação, os obstáculos inesperados que participarão da solução da problemática, atuando como agentes de alteridade, promovendo todo tipo de desvio que facilite a resolução dos complexos da diferenciação. Salles (1998, p. 33-34) associa tais obstáculos à noção de acaso, pensando-o como um atributo desviante, posicionando-o quase em termos dicotômicos em relação à noção de tendência. O que Salles chama de acaso pode ser entendido como um fator desviante, intrínseco ao processo de diferençação, que acontecerá inevitavelmente, em maior ou menor medida, independentemente de haver ou não algum fator arbitrário de produção do inesperado no processo; talvez não seja o acaso que seja acolhido pelo artista, e sim o artista que se joga em um movimento de produção de diferença, de sair de si:

A atualização do virtual, ao contrário, sempre se faz por diferença, divergência ou diferençação. A atualização rompe tanto com a semelhança como processo quanto com a identidade como princípio. Os termos atuais 
nunca se assemelham à virtualidade que eles atualizam: as qualidades e espécies não se assemelham às singularidades que elas encarnam. A atualização, a diferençação, neste sentido, é sempre uma verdadeira criação (Deleuze 2018, p. 280).

A distinção entre os pares possível-real e virtual-atual se acentua no fato de que aquilo que é virtual, ao se atualizar, produz a diferença, como bem observa Pierre Lévy (2011, p. 17): “o real assemelha-se ao possível; em troca, o atual em nada se assemelha ao virtual: responde-lhe". Além disso, conforme Henriques,

Para Deleuze, a diferença entre eles reside no fato de que o possível sempre foi pensado pela tradição como uma instância ideal a que falta a realidade (e daí a necessidade de ele se "realizar"), ao passo que o virtual é algo a que não falta nenhuma realidade: ele não é um conjunto de possibilidades dado num intelecto humano ou divino, mas a própria parte ideal do real, algo tão real quanto os próprios corpos e os estados de coisa. Há também uma segunda diferença marcante entre eles, para Deleuze, a saber: que há entre o possível e sua realização uma clara relação de semelhança, pois o possível é basicamente o conceito da coisa sem sua efetivação material (o que comumente chamamos de "forma"), ao passo que entre o virtual e sua atualização reside uma profunda dessemelhança, dado que o virtual consiste basicamente numa questão ideal que encontrará seu esboço de solução na atualização dele derivada, devendo-se observar que entre essa questão e sua solução não pode haver nenhuma relação de semelhança [...]. O virtual se distingue, assim, claramente do possível (Henriques 2016, p. 184-185).

Deste modo, o possível que vem do real pode ser visto como a simples efetivação de um estado (para Bergson, somente passível de ser conhecido após ter sido realizado), enquanto o virtual que se atualiza é a invenção de solução para um complexo problemático. $\mathrm{O}$ virtual e o atual coexistem como realidades distintas, enquanto aquilo que já foi atualizado comporta o conjunto das coisas possíveis no real.

Podemos pensar o possível como a página de um texto que viramos após escrevê-lo. O possível é o registro, a notação, a intelecção imediata, a experiência que acaba de se tornar passado, o que acabou de acontecer; ele jamais poderá ser confundido com o fator ígneo que alimenta o processo criativo. A ideia não se origina no possível, pois nada de novo pode surgir no que já foi: a escrita acontece na próxima página em branco, e não naquela que foi virada. Pensar o possível como originário de um processo significa forçar um transcendentalismo em um 
MUSICA THEORICA Revista da Associação Brasileira de Teoria e Análise Musical 2019, v. 4, n. 1, p. 234-254-Journal of the Brazilian Society for Music Theory and Analysis@ TeMA 2019 - ISSN 2525-5541

campo de criação que depende de uma imanência da atualização. Nesse sentido, Salles comenta que

Não se pode limitar o conceito de processo com tendência, nesse contexto de uma obra específica, a um grande insight inicial. Se assim fosse visto, o processo de criação seria um percurso quase mecânico de concretização de uma grande ideia que surge no começo do processo. No contato com diferentes percursos criativos, percebe-se que a produção de uma obra é uma trama complexa de propósitos e buscas: problemas, hipóteses, testagens, soluções, encontros e desencontros. Portanto, longe de linearidades, o que se percebe é uma rede ele tendências que se inter-relacionam (Salles 1998, p. 36).

\section{Planos de organização e de consistência (ou o Plano)}

O que Salles aponta vai de encontro com duas maneiras de pensar o plano de criação sugeridas por Deleuze e Guattari no quarto volume de Mil Platôs. Segundo Döbereiner, o termo "plano" pode indicar tanto a noção de um campo de ação quanto um lugar para o planejamento formal:

No volume de Mil Platôs de 1980 Deleuze e Guattari identificam dois modos opostos de conceitualizar o que eles chamam de "planos". Haveria duas maneiras distintas de pensar as dimensões da criação, um "absoluto localizado" compartilhado por atos conceituais singulares de criação. A formulação ambígua do termo "planos" serve tanto para significar um plano ontologicamente neutro, ou seja, um plano não hierárquico ou um horizonte conceitual que serviria para orientar o pensamento filosófico, quanto um plano ou estrutura da composição artística (Döbereiner 2014, p. 269).

Nesse sentido, para Deleuze e Guattari haveria dois tipos distintos de plano: planos de organização e planos de consistência. O plano de organização é aquele que, no contexto da composição musical, corresponde ao não audível, ao que não está dado no mundo sonoro da música, ao que ocupa uma posição transcendente em relação ao som.

Assim como na música, o princípio de organização ou de desenvolvimento não aparece por si mesmo ou para si mesmo. Isto permite todas as interpretações possíveis. As formas e seus desenvolvimentos, os sujeitos e suas formações remetem a um plano que opera como unidade transcendente ou princípio oculto. Poderemos sempre expor o plano, mas como uma parte à parte, um não-dado naquilo que ele dá (Deleuze; Guattari 2012, p. 57).

Para entendermos melhor o que Deleuze e Guattari querem dizer neste trecho do texto, é necessário contextualizar ao que exatamente esses autores se 
referem ao falar de um campo de organização transcendente. Logo após o trecho citado acima, os autores mencionam o compositor Karleinz Stockhausen: "mas também Stockhausen não precisa expor a estrutura de suas formas sonoras como que 'ao lado' delas, na falta de fazer ouvi-la?" (Ibidem).

Podemos perceber nessa questão que os autores estão se referindo às estruturas abstratas dos sistemas composicionais. Especificamente, no caso de Stockhausen, aos materiais pré-composicionais: séries, grupos e fórmulas. Isto é corroborado por Döbereiner, que escreve:

Deleuze e Guattari enxergam um exemplo de modelo composicional inaudito no trabalho de Karlheinz Stockhausen, o qual eles interpretam como sendo baseado em uma unidade transcendental escondida, um princípio que cria formas, mas que nunca aparece por si só e pode apenas ser inferido dessas formas. De fato, este modo de pensar é mais presente e claramente discernível na música serial de Stockhausen da década de 1950. Defendendo a inaudibilidade da ordem serial, Stockhausen escreve, "quem enxerga os átomos? Ainda assim, todos sabem que toda a aparência da matéria depende de sua estrutura" (Döbereiner 2014, p. 270).

O plano de organização, no contexto da composição musical, está relacionado com a organização conceitual dos processos composicionais. A escolha das técnicas, o pensamento sobre a forma, sobre os materiais, e até mesmo conceitos elementares (como altura, duração, dinâmica, textura, densidade, timbre) protagonizam este plano. Nesse sentido, o plano de organização é prévio à concretização sonora.

O plano de organização não se situa em uma posição transcendente em relação ao todo do processo composicional (se assim fosse, elas seriam inacessíveis dentro do próprio processo); a transcendência aí se encontra na perspectiva perceptiva do receptor em relação à organização estrutural - ou seja, é transcendente para o ouvinte que não escuta as séries, que não conhece as fórmulas, que não participou das manipulações estruturais, mas que frui o resultado sonoro de tais organizações.

Assim, percebe-se que a transcendência do plano de organização não é absoluta - para o compositor, os conceitos que constituem esse plano surgem de 
MUSICA THEORICA Revista da Associação Brasileira de Teoria e Análise Musical 2019, v. 4, n. 1, p. 234-254-Journal of the Brazilian Society for Music Theory and Analysis @ TeMA 2019 - ISSN 2525-5541

forma imanente em sua imaginação; em outras palavras, o plano de organização é constituído sobre um plano de imanência. ${ }^{7}$

Este plano imanente corresponde ao que Deleuze e Guattari (2012, p. 5758) irão chamar de plano de consistência. Nele não cabe qualquer transcendência. Neste plano, as coisas são causas de si mesmas e nada do que acontece tem uma existência a priori. Deleuze e Guattari atribuem a esse plano a proliferação, o povoamento, mas sem que haja nele um princípio teleológico embutido; nele não há finalidade ou evolução. Este plano é análogo às instâncias do "acaso" mencionadas anteriormente por Salles. Döbereiner (2014, p. 270-271) escreve que “esse plano 'nunca tem uma dimensão suplementar' da qual um princípio oculto poderia funcionar; ao invés disso, ele é dado por si só naquilo que faz surgir". $\mathrm{O}$ plano de consistência pode ser relacionado com o "acaso" no sentido de, ao afirmar sua natureza imanente, ser portador de uma capacidade de "destruição" do princípio transcendente.

Devemos questionar de que modo esses campos se relacionam com o virtual e o atual. Poder-se-ia imaginar que tais campos seriam correlatos aos conceitos prévios, o que significa dizer que o plano de organização corresponde ao virtual e o plano de consistência ao atual. O plano de organização contém aspectos do virtual, pois nele residem as relações conceituais, as estruturas e formas. Contudo, ele é construído justamente à revelia das multiplicidades do virtual. Para ilustrar essa afirmação, consideremos o seguinte exemplo:

Um compositor trabalha mentalmente em uma peça para quarteto de cordas. Em sua imaginação, ele começa a delinear a primeira frase do violoncelo, e esta frase contém algumas durações e um perfil rítmico definido. Estes são elementos do plano de organização - todo os elementos restantes, não definidos, não estão contidos no plano de organização e são, contudo, elementos do virtual, componentes da ideia que gerarão problemáticas no momento da atualização, tais como: 1) qual será o tratamento timbrístico? 2) quais serão as dinâmicas? 3) que tipos de golpe de arco serão empregados?

Essas questões serão respondidas no campo de consistência, que inclui os modos de atualizar a ideia empregados pelo compositor (que podem ser o solfejo, a notação, a improvisação ao instrumento, o computador). Deste modo, podemos

\footnotetext{
${ }^{7}$ Deleuze e Guattari (2010, p. 47) escrevem, em O que é a Filosofia, que "o plano de imanência não é um conceito pensado nem pensável, mas a imagem do pensamento, a imagem que ele se dá do que significa pensar, fazer uso do pensamento, se orientar no pensamento".
} 
considerar os planos de organização e de consistência como "áreas de trabalho", onde a primeira refere-se às concatenações entre conceitos e a segunda às germinações do virtual no atual. É neste sentido que podemos considerar que ambos os planos estão integrados em uma dinâmica:

De modo que o plano de organização não para de trabalhar sobre o plano de consistência, tentando sempre tapar as linhas de fuga, parar ou interromper os movimentos de desterritorialização, lastreá-los, reestratificá-los, reconstituir formas e sujeitos em profundidade. Inversamente, o plano de consistência não para de se extrair do plano de organização, de levar partículas a fugirem para fora dos extratos, de embaralhar as formas a golpe de velocidade ou lentidão, de quebrar as funções à força de agenciamentos, de microagenciamentos (Deleuze; Guattari 2012, p. 63).

Apesar de seguir uma linha teórica completamente distinta, Richard Willgross apresenta, em seu artigo intitulado Creativity in Contemporary Art Music Composition, uma imagem muito similar à das dinâmicas entre os planos de organização e consistência de Deleuze e Guattari:

Primeiramente nós descobrimos que aquela arte, em particular a musical, se revolta contra conceitos essenciais baseados na razão, sem a qual, paradoxalmente, a arte é inconcebível em primeiro lugar. A arte debilita os conceitos para deixar o não-conceitual falar. Em segundo lugar, a razão estrutura para reprimir e subordinar a novidade, mas a arte, invariavelmente relacionada ao novo, não é redutível à razão (Willgross 2012, p. 425).

Sugerimos, assim, que o processo composicional não é simplesmente a efetivação de um princípio teleológico: pensando o virtual e o atual dentro de tais processos, poderemos entender melhor o papel dos planos - considerando que planos de organização e de consistência tendem a se aniquilar mutuamente, produzindo um "resto" ou uma "sobra" no real que vem a ser a música concretizada. Os planos de organização e consistência funcionam como polos codependentes, como movimentos da ideia no pensamento e no ato.

Em termos práticos, não há planejamento propriamente estrito de uma obra, mas sim estes planos, movimentos da diferença no virtual e no atual a partir dos quais a obra poderá crescer e se desenvolver. Deleuze já havia comentado que as imagens virtuais reagem sobre o atual; nesta reação temos um processo de virtualização em andamento, no qual o ato funda novas questões no campo do 
MUSICA THEORICA Revista da Associação Brasileira de Teoria e Análise Musical 2019, v. 4, n. 1, p. 234-254-Journal of the Brazilian Society for Music Theory and Analysis@ TeMA 2019 - ISSN 2525-5541

virtual; quando o atual reestrutura o virtual, provocando o seu a-fundamento, o objeto é virtualizado. ${ }^{8}$

As imagens virtuais não são mais separáveis do objeto atual que este daquelas. As imagens virtuais reagem, portanto, sobre o atual. Desse ponto de vista, elas medem, sobre o conjunto de círculos ou sobre cada círculo, um continuum, um spatium determinado em cada caso por um máximo de tempo pensável. A esses círculos mais ou menos extensos de imagens virtuais, correspondem camadas mais ou menos profundas do objeto atual. Estes formam o impulso total do objeto: camadas virtuais, e nas quais o objeto atual torna-se, por sua vez, virtual. Ambos, objeto e imagem, são aqui virtuais, e constituem o plano de imanência onde se dissolve o objeto atual (Deleuze; Parnet 1998, p. 174).

O objeto virtualizado se abre a novos nós problemáticos, engendra novas diferenciações, retroalimentando o fluxo criativo. Do ponto de vista deste fluxo, a virtualização é a última etapa do giro de um processo de aquisição de concretude da composição musical, seja esta aquisição um acontecimento em performance musical ou notacional. ${ }^{9}$

A virtualização, enfim, passa do ato - aqui e agora - ao problema, aos nós de coerções e de finalidades que inspiram os atos. [...]

A virtualização sai do tempo para enriquecer a eternidade. Ela é a fonte dos tempos, dos processos, das histórias, já que comanda, sem determiná-las, as atualizações. Criadora por excelência, a virtualização inventa questões, problemas, dispositivos geradores de atos, linhagens de processos, máquinas de devir (Lévy 2011, p. 140).

Para Deleuze e Parnet (1998, p. 173), "não há objeto puramente atual". Com isso, o filósofo quer dizer que o processo de reconhecimento dos objetos implica na existência de um circuito virtual-atual-virtual no modo de percebêlos, que exige uma mobilidade dos campos virtuais envolvidos. Esta noção de circuitos se adequa à visão de Bergson (1990, p. 112) que diz que "a lembrança se transforma à medida em que se atualiza". Como exemplo, podemos pensar em escutas repetidas de uma mesma obra musical: cada circunstância de escuta

\footnotetext{
${ }^{8}$ Nas notas de rodapé anteriores, comentamos brevemente a relação do a-fundamento com a terceira síntese do tempo em Deleuze. Para um aprofundamento do conceito, ver o tópico "O que é decisivo no problema da diferença: o simulacro, a resistência do simulacro" em Diferença e Repetição (2018, p. 95-99).

${ }^{9}$ A atualização pode ocorrer tanto na produção de um som quanto em alguma forma de escrita (partituras, rascunhos, anotações etc.).
} 
implica em instantes do tempo que não se repetem, em diferentes configurações afetivas, de memória, de contexto e de atenção. Não se percebe duas vezes um mesmo objeto da mesma maneira, pois a percepção atualiza as lembranças de um passado virtual.

Nesse sentido, não há contemporaneidade absoluta entre sujeito e objeto, pois, por sermos seres lentos, nossos organismos contraem o presente em passado, projetando lembranças sobre as percepções, transformando o mundo da matéria (velozes movimentos de partículas e ondas) em unidades e qualidades estáveis - como as sensações de sons e cores. Como bem aponta Henriques (2016, p. 126), “todo objeto real percebido por nós nunca é algo simplesmente atual, pois nele há sempre uma contraparte virtual, que não é nada mais que as lembranças que projetamos sobre ele a fim de dotá-lo de um sentido".

A noção de que o reconhecimento dos objetos está calcado nos circuitos virtuais-atuais-virtuais nos permite pensar a ideia musical como uma esfera passível de mudança: algo no atual pode ocasionar uma alteração na ideia. Este é o ponto em que mais nos distanciamos do pensamento platônico, no qual a ideia é tida como eterna e imutável: a diferença se manifesta não só no produto do atual como também no campo virtual que lhe deu origem. $O$ desvio se opera não só na obra, mas também, simultaneamente, no projeto: ${ }^{10}$

Como já foi dito em relação à natureza da tendência em sentido amplo, o percurso criativo conhece uma lenta definição do projeto poético do artista. O tempo da criação seria o tempo da configuração do projeto. Pode-se, assim, dizer que o processo de criação de uma obra é a forma do artista conhecer, tocar e manipular seu projeto de caráter geral (Salles 1998, p. 39).

Fazendo mais um paralelo entre Salles e o quarto volume de Mil Platôs de Deleuze e Guattari, nos é dado um outro modo de descrever este mesmo percurso:

[...] o plano, plano de vida, plano de escrita, plano de música etc., só pode fracassar, pois é impossível ser-lhe fiel; mas os fracassos fazem parte do

\footnotetext{
${ }^{10}$ Esta imagem relaciona-se com a noção deleuziana de $a$-fundamento na terceira síntese do tempo. Se a primeira síntese do tempo (o presente) funda o tempo e a segunda (o passado) o fundamenta, a terceira síntese o a-funda: é o futuro que faz passar o presente e destrói a materialidade do passado; o a-fundamento é responsável, portanto, por reconfigurar as outras sínteses do tempo, por "sabotar" a fundação e o fundamento.
} 
MUSICA THEORICA Revista da Associação Brasileira de Teoria e Análise Musical 2019, v. 4, n. 1, p. 234-254-Journal of the Brazilian Society for Music Theory and Analysis @ TeMA 2019 - ISSN 2525-5541

plano, pois ele cresce e decresce com as dimensões daquilo que ele desenvolve a cada vez (Deleuze; Guattari 2012, p. 62).

Sugerimos, aqui, que a noção de um platonismo do processo composicional, caracterizado por um planejamento norteador e assertivo de um conjunto de conceitos a serem totalmente materializados ou de um macroprojeto formal a ser efetuado, não corresponde às dinâmicas do processo de criação, pois "há uma forte relação entre tendências e desafios que, para se manterem como tais, precisam estar sempre em mutação"11 (Salles 1998, p. 31); ou seja, a ideia, longe de ser imutável e perfeita, deve ser tão maleável quanto o produto do ato, o que é um outro modo de dizer que o atual interfere no virtual.

Entretanto, não negamos que existe um plano de organização nos processos composicionais. Contudo, a suposta teleologia implicada na existência destes elementos por si só não constitui, resume ou explica o aspecto criativo neste caso, é necessário levar em conta a multiplicidade do virtual.

\section{Considerações finais}

Não é possível fazer um corte no fluxo criativo ${ }^{12}$ e apontar com exatidão onde o virtual se atualiza ou onde o atual se virtualiza. $O$ fluxo criativo corre continuamente, as ideias surgem e perpassam os planos: o atrito entre os planos produz uma sobra: objetos que "escapam" dos planos durante a atualização.

[...] todos os planos se confundem, conforme a via que leva ao atual. O plano de imanência compreende, a um só tempo, o virtual e sua atualização, sem que possa haver limite assinalável entre os dois. O atual é o complemento ou o produto, o objeto da atualização, mas esta só tem por sujeito o virtual. A atualização pertence ao virtual. A atualização do virtual é a singularidade, enquanto o próprio atual é a individualidade constituída. $\mathrm{O}$ atual cai para fora do plano como fruta, enquanto a atualização o relaciona ao plano como ao que reconverte o objeto em sujeito (Deleuze; Parnet 1998, p. 175).

Devemos nos lembrar de evitar pensar o virtual como um campo a priori constituidor da realidade - isso seria o mesmo que confundir o real com o

11 Traçando um paralelo com o conceito de a-fundamento, o desvio desfigura não só a materialidade da obra em relação à Ideia na atualização, mas também promove uma transformação na própria Ideia no virtual: se a Ideia não possui rigidez, se não é eterna e imutável, isto inviabiliza qualquer forma de platonismo.

${ }_{12}$ Do mesmo modo como, para Bergson (1990, p. 154-158), não é possível cortar ou dividir o movimento. 
possível, ou atribuir ao virtual a qualidade transcendental que já negamos ao possível. $\mathrm{O}$ virtual diz respeito às diferenciações e suas questões, enquanto o atual tem a ver com as respostas das diferençações, e ambos participam do real ao mesmo tempo - virtual e atual não estão, portanto, separados, mas congregam a realidade do mesmo objeto, de modo que o virtual não é algo que tenha qualquer precedência sobre o mundo dos objetos, e sim uma das metades do processo de constituição do real (a atualização sendo a outra metade). Henriques comenta que

Com efeito, pensar o virtual como uma espécie de fundamento ideal do atual seria na verdade concebê-lo como um campo de possibilidades que se realizaria nos corpos e estados de coisa. Ora, reduzir o virtual ao possível seria, como vimos, o maior erro que poderíamos cometer. Longe de ser uma espécie de fundamento oculto do atual, o virtual deve antes ser pensado, para Deleuze, como a instância problematizadora e questionante da Ideia, ao passo que o atual seria a instância de resolução dos problemas, de resposta às questões (Henriques 2016, p. 190).

Assim, o virtual e o atual podem ser considerados como modos simultâneos de constituição do real. Nesse sentido, Henriques (2016, p. 183) escreve que "o virtual deleuziano é uma parte da estrutura ontológica do real, a qual comporta tanto um polo material e atual (os corpos e os estados de coisa), quanto um polo ideal e virtual (a ideia ou o sentido)". A “ilusão" da ideia como um princípio nos processos composicionais se explica pelo mesmo mecanismo que faz com que consideremos o possível como algo que antecede o real: ao lidarmos com a ideia, que surge imanente como uma imagem mental, imediatamente a projetamos no passado e a consideramos pertencente a uma realidade a priori. Ao nos darmos conta da qualidade imanente da ideia musical, o fluxo criativo pode ser visto como um acontecimento de captura em tempo real das forças do virtual e de sua imediata atualização nos corpos:

Para Deleuze, a questão da arte, sua problemática, não é a criação de formas, e sim a "captura de forças". Para haver uma sensação lá, uma força precisa ser enxertada em um corpo. A força, contudo, não é dada ou sentida em si, ao invés disso ela permanece virtual, e é a tarefa da arte fazer com que essas forças imperceptíveis se tornem perceptíveis (Döbereiner 2014, p. 281).

É nesse contexto que Deleuze e Guattari (2012, p. 174) escrevem que "é desde sempre que a pintura se propôs a tornar visível, ao invés de reproduzir o visível, e a música a tornar sonoro, ao invés de reproduzir o sonoro"; nesta 
colocação está o resumo de toda a crítica à lógica da representação apresentada neste texto. A questão dos processos composicionais encontra aí sua formulação mais clara, que sempre será resolvida no próprio ato de compor: o problema de traçar um continuum entre o intensivo e o extensivo, entre o plano de organização e o de consistência, em atualizar um virtual e virtualizar um algo do atual, em enxertar e extrair forças dos corpos. Assim, conforme o comentário do compositor Silvio Ferraz (2005, p. 69), “não se diz mais que é música aquilo que é sonoro, mas sim que fazer música é tornar sonoro forças não sonoras: forças de crescimento, forças de conexão humana, forças de guerra, forças táteis, forças visuais etc.". O fluxo composicional deixa de ser teleológico, de ir de A para B de perseguir a meta da música ideal ao se jogar subitamente nos planos de imanência, nos jogos de intensidade, nos movimentos dos ritornelos - para girar nos ciclos de atualização e virtualização e desviar cada vez mais do seu centro, inaugurando, a cada nova órbita, relações gravitacionais inauditas.

\section{Referências}

1. Aristóteles. 2018. Metafísica. São Paulo: Edições Loyola.

2. Assis, Paulo de. 2018. Virtual works-Actual things. In: Essays in music ontology, p. 19-43. Leuven: Leuven University Press.

3. Bergson, Henri. 2006. O pensamento e o movente. São Paulo: Martins Fontes.

4. 1990. Matéria e memória. São Paulo: Martins Fontes.

5. Deleuze, Gilles. 2018. Diferença e Repetição. Rio de Janeiro/São Paulo: Paz e Terra.

6. 2012. Bergsonismo. São Paulo: 34.

7. 2002. A imanência: uma vida... In: Educação e Realidade, n. 27, v. 2 , p. $10-18$.

8 . 2011. Lógica do sentido. São Paulo: Perspectiva.

9. Deleuze, Gilles; Guattari, Felix. 2012. Mil platôs, v. 4. São Paulo: 34. 10 . . 2010. O que é a filosofia? São Paulo: 34.

11. Deleuze, Gilles; Parnet, Claire. 1998. Diálogos. São Paulo: Editora Escuta.

12. Döbereiner, Luc. 2014. The virtuality of the composition model: Varèse with Deleuze. In: Acta Musicologica, v. 86, Fasc. 2, p. 267-285. 
13. Durozoi, Gérard; Roussel, André. 1993. Dicionário de filosofia. Campinas: Papirus.

14. Ferraz, Silvio. 2005. Livro das sonoridades: notas dispersas sobre composição. Rio de Janeiro: 7Letras.

15. Henriques, Fernando Meireles Monegalha. 2016. O atual e o virtual em Bergson e Deleuze. Tese (Doutorado em Filosofia) - Universidade Federal de São Carlos.

16. 15. Klee, Paul. 1971. Teoria del arte moderno. Buenos Aires: Ediciones Caldén.

17. Lévy, Pierre. 2011. O que é o virtual. 2ª edição. São Paulo: Editora 34.

18. Salles, Cecília Almeida. 1998. Gesto inacabado: processo de criação artística. São Paulo: FAPESP.

19. 2006. Redes de criação: construção da obra de arte. São Paulo: Editora Horizonte.

20. Willgross, Richard. 2012. Creativity in contemporary art music composition. International Review of the Aesthetics and Sociology of Music, v. 43, n. 2, p. 423437. 